\title{
About the effectiveness of a hydrophobic surface treatment of Baumberger Sandstones
}

\author{
Jeanette Orlowsky ${ }^{1}$ Melanie Groh ${ }^{1}$ (D) $\cdot$ Franziska Braun ${ }^{2}$
}

Received: 20 June 2021 / Accepted: 10 November 2021 / Published online: 31 January 2022

(c) The Author(s) 2022

\begin{abstract}
The Baumberger Sandstone, a sandy limestone, is used since the Middle Ages as a building material not only in the surrounding Münster region of North Rhine-Westphalia (Germany), where it is quarried since to date. To prevent the ingress of water and reduce weathering processes conservation methods, mostly in form of organosilicon compounds, were used. This study deals with the performance of applied hydrophobing agents on Baumberger Sandstone samples and their influence on the weathering processes during long-term exposure. The samples were exposed at several locations in Germany to different climatic conditions for up to 24 years. Afterwards, investigations concerning the water absorption behaviour and the degree of superficial damages were carried out. With an evaluation method on basis of NMR measurements, a very low and uneven distributed effective hydrophobic zone could be detected. This caused an ingress of water in the uppermost part and a progressive weathering of investigated natural stones. Thus the hydrophobic surface treatment did not lead to a significant decrease of weathering or damaging processes. Based on these results a hydrophobic surface treatment of Baumberger Sandstone seems not to be suitable.
\end{abstract}

Keywords Baumberger Sandstone $\cdot$ Long-term weathering $\cdot$ Hydrophobing agent $\cdot$ Conservation $\cdot$ Durability $\cdot$ Single-sided NMR

\section{Introduction}

\section{Origin of the sample material}

The decay and conservation of natural stones were investigated in a BMFT (Federal Ministry of Research and

This article is part of a Topical Collection in Environmental Earth Sciences on "Building Stones and Geomaterials through History and Environments - from Quarry to Heritage. Insights of the Conditioning Factors", guest edited by Siegfried Siegesmund, Luís Manuel Oliveira Sousa, and Rubén Alfonso López-Doncel.

Melanie Groh

melanie.groh@tu-dortmund.de

Jeanette Orlowsky

jeanette.orlowsky@tu-dortmund.de

Franziska Braun

braun@ifs-mainz.de

1 Chair of Building Materials, TU Dortmund University, August-Schmidt-Str. 8, 44227 Dortmund, Germany

2 Institute for Stone Conservation E.V., Große Langgasse 29, 55116 Mainz, Germany
Technology, Germany) Priority Programme from 1985 to 1996. More than twenty institutes were involved in this joint research project, which focused on the research of causes of the deterioration of natural stones, their damage mechanisms as well as their repair and protection. Part of this work were several outdoor field studies, which were aimed to characterise the weathering behaviour of certain stone materials under various influencing factors, but also to investigate the effect of protective agents (Brüggerhoff and Wagener-Lohse 1989). The Zollern Institute (today: Deutsches Bergbau Museum, Bochum) performed such a study, where the natural stone samples in this article are related to (Mirwald 1986; Brüggerhoff and Wagener-Lohse 1989). Between 1986/87 and 2010 (resp. 2017 for other stone types) two untreated and eleven samples treated with different hydrophobing agents based on organosilicon compounds were exposed at several sites in Germany (Fig. 1). All locations are characterised by different climatic conditions and emission loads (Orlowsky et al. 2020). In addition, specimens were stored in an archive in Bochum, Germany, over the entire period and served as reference. 

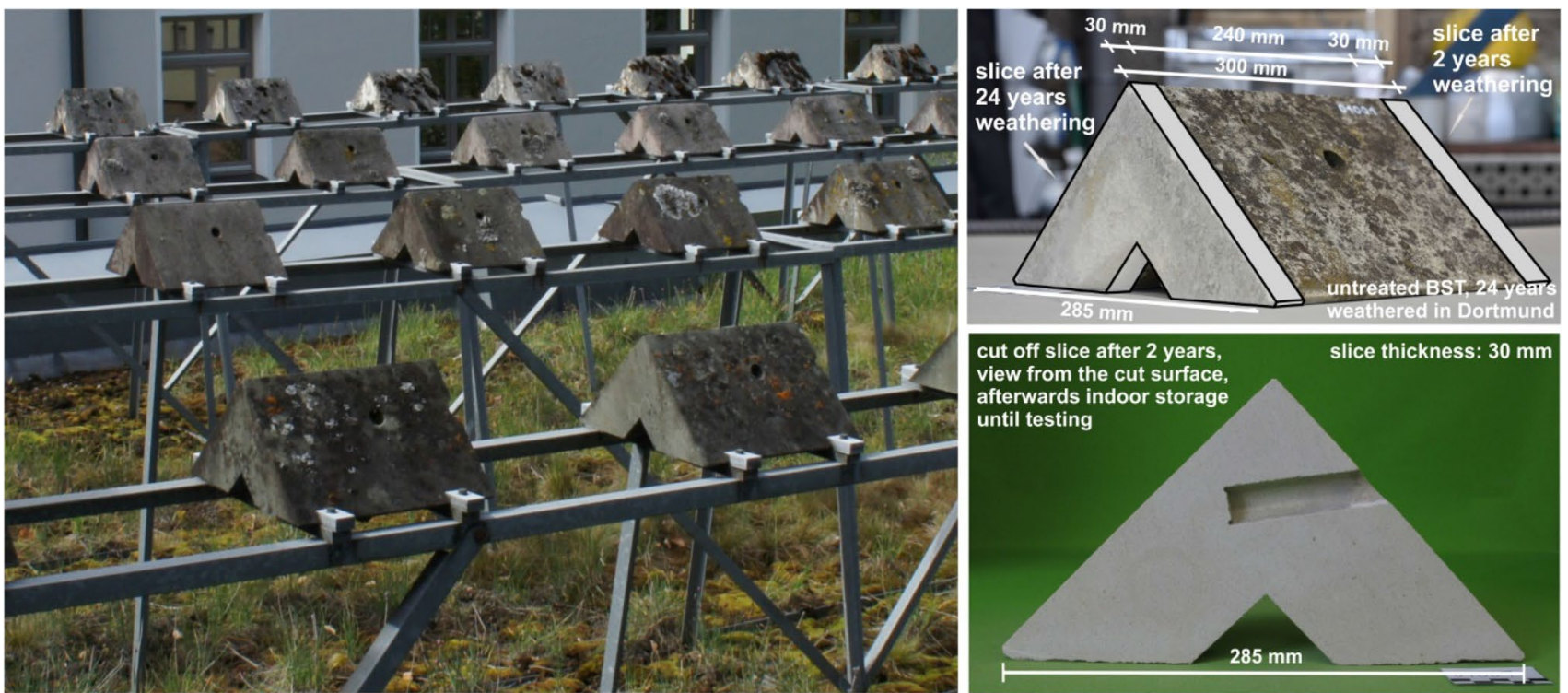

Fig. 1 Outdoor exposure field study and triangular prismatic shaped specimens of the Baumberger Sandstone, from which $30 \mathrm{~mm}$ thick slices were taken from the vertically oriented side surfaces after 2 and 17 resp. 24 years of outdoor weathering

The specimens of the field study have a triangular prismatic shape to simulate typical conditions at buildings. Before outdoor exposure, the samples were treated by complete immersion in a hydrophobing agent bath for 1 min (Fig. 2). The prisms dried for several weeks in indoor climate, standing upright on spacers and then on styrofoam. Subsequently, they were set up at different sites in North Rhine-Westphalia (Dortmund, Duisburg and Eifel) for 24 years until 2010. The other stone types of this field study were additionally placed at three sites in Bavaria (Nuremberg, Munich and Kempten) for 30 years.
Climatic data and pollutant values on the sites during the last 10 years of exposure can be found in Orlowsky et al. (2020). After 2 years a $3 \mathrm{~cm}$ thick sample was cut off each prism (Fig. 1) and further stored indoors, while the prisms were sealed with epoxy resin on the cut surface and exposed again. After a total exposure time of 17 or 24 years, respectively, the samples were removed from the sites and stored in an archive until testing. The complete sample preparation and examination was done at the Chair of Building Materials at TU Dortmund University between 2017 and 2019.

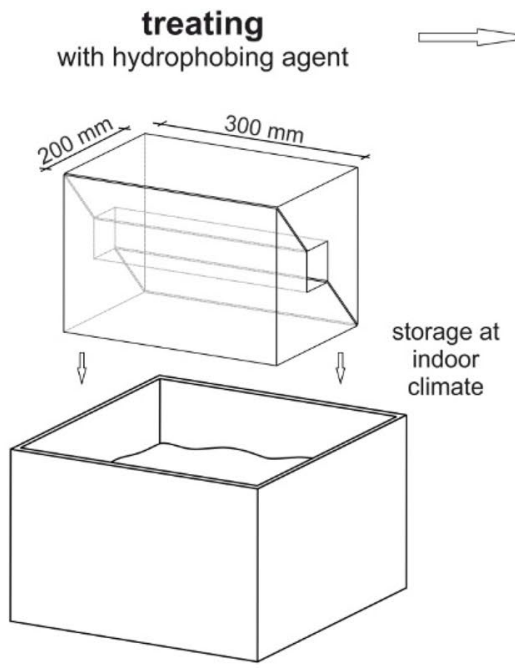

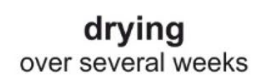

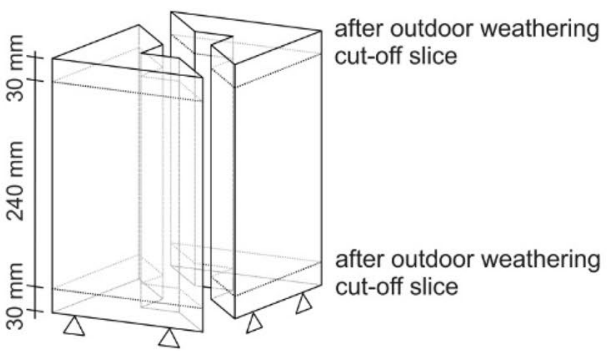

\section{outdoor weathering \\ at different exposition sites and expositon times}

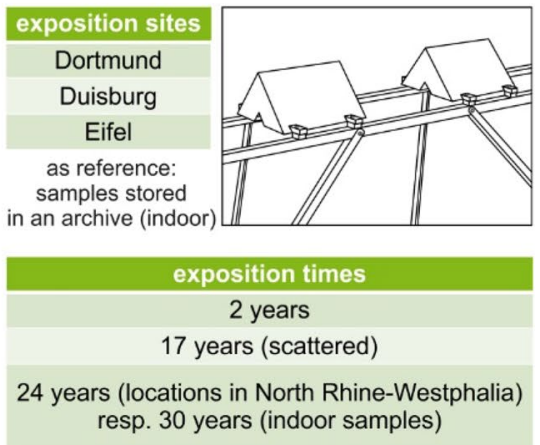

flood-process (immersion time: 1 minute)

Fig. 2 Appling the hydrophobic surface treatment on the Baumberger Sandstone prisms and preparing them for the outdoor field study 


\section{Baumberger Sandstone as a building material}

Baumberger Sandstone has been used since the Middle Ages as a building and sculpture stone due to its facile workability. It is quarried west of Münster near Havixbeck on the northern edge of the Baumberge mountains. It was mainly used for ornaments and sculptures, but also for load-bearing masonry. Since the end of the fifteenth century until now, the Baumberger Sandstone is primarily material for corner decorations on masonry at new buildings and plays an important role in the preservation of historical monuments as restoration material (Hafner 1988). The Baumberger Sandstone as a building stone characterises the townscape of Münster with his townhall and adjoining buildings as well as the surrounding Münster region. Other significant buildings using this material are St. Paul's Cathedral in Münster, the cathedral in Xanten and the Cologne Cathedral.

The Baumberger Sandstone is a yellowish-grey (10 YR $8 / 2$ - 5 Y 7/2) sandy limestone with a calcareous-clayey matrix. The mineralogical composition consists of about $55 \%$ calcite, mainly originating from fossil fragments (such as echinoderms, foraminifera, shell and coral fragments as well as sponge remains), about $25 \%$ quartz (sand and silt grain size) and about $5 \%$ clay minerals. In addition it may also contain of up to $15 \%$ glauconite. Concerning the petrophysical properties, the Baumberger Sandstone has a total porosity of about $20 \%$, with a bulk density of $2.17 \mathrm{~g} / \mathrm{cm}^{3}$ and an apparent density of $2.73 \mathrm{~g} / \mathrm{cm}^{3}$, whereby the majority of the fine pore spaces are present in the micritic matrix (Braun et al. 2020; Braun 2021). The capillary water absorption coefficient is about $2 \mathrm{~kg} / \mathrm{m}^{2} \sqrt{\mathrm{h}}$ and after $1 \mathrm{~h}$ water absorption by pipe method values of $0.4 \mathrm{ml} / \mathrm{cm}^{2}$ can be determined.

Due to its weakly consolidated microporous structure, the Baumberger Sandstone shows moderate to poor weathering resistance (e.g., black gypsum crusts, scaling, sanding) (Braun et al. 2020), which illustrates the necessity of conservation measures. In contrast to siliceous stone types, stone protecting agents on an organosilicon basis are merely insufficiently chemically bound via the carbonate structure of the Baumberger Sandstone, which is why the success of water repellent surfaces treatments have to be regarded as problematic.

\section{Used hydrophobing agents}

For the field study in 1986/87 different silanes, siloxanes and silicone resins with variated contents were used as protective agents (Table 1). Agents 3-5 and 10 additionally contain silicic acid esters as coupling agent. Nowadays primarily the higher concentrated silanes are still available, whereby environmental regulations leading to used solvents being replaced more and more by water-based systems. To be able to assess protective measures carried out in the past, a consideration of siloxane and silicone resin systems is also of interest. To determine the amount of active ingredient absorbed during the flood-process, the samples were weighed before and immediately after impregnation. Table 1 shows the absorbed amounts of all prisms with an average value of $200 \mathrm{~g} / \mathrm{m}^{2}$.

\section{Experimental methods}

\section{Optical penetration depth of the hydrophobing agents}

To detect the visual penetration depth of the hydrophobing agents, the samples, which were conditioned in the

Table 1 Used protective agents and the absorbed amount of active ingredient for each prism

\begin{tabular}{|c|c|c|c|c|c|}
\hline \multirow[t]{2}{*}{ Agent ID } & \multirow[t]{2}{*}{ Chemical composition and content (M.-\%) } & \multicolumn{4}{|c|}{ Absorbed amount of active ingredient $\left(\mathrm{g} / \mathrm{m}^{2}\right)$} \\
\hline & & Indoor & Dortmund & Duisburg & Eifel \\
\hline 0 & Untreated Baumberger Sandstone (BST), 2a indoor (reference) & - & & & \\
\hline 1 & $34 \%$ propyl- $/ 5 \%$ octyltrimethoxysilane & 158 & 155 & 169 & 163 \\
\hline 2 & $35 \%$ isobutyltrimethoxysilane & 156 & 164 & 164 & 154 \\
\hline 3 & $20 \%$ isobutyltrimethoxysilane $+20 \%$ tetraethoxysilanehydrolysat & 131 & 134 & 142 & 137 \\
\hline 4 & $20 \%$ isobutyltrimethoxysilane $+20 \%$ tetraethoxysilane & 152 & 152 & 146 & 155 \\
\hline 5 & low-molecular methylethoxysiloxane + tetraethoxysilane $\left(\sum 75 \%\right)$ & 207 & 196 & 193 & 210 \\
\hline 6 & 7.5\% low-molecular methylethoxysiloxane & 222 & 227 & 326 & 223 \\
\hline 7 & $6.7 \%$ oligomer methylethoxysiloxane & 219 & 218 & 212 & 206 \\
\hline 8 & $5 \%$ methyl-/isooctyl silicone resin & 242 & 249 & 262 & 242 \\
\hline 9 & $6.7 \%$ oligomer methyl-/isooctylmethoxysiloxane & 211 & 223 & 223 & 266 \\
\hline 10 & oligomer methyl-/isooctylmethoxy-siloxane + tetraethoxysilane $\left(\sum 8.3 \%\right)$ & 227 & 201 & 186 & 196 \\
\hline 11 & $\begin{array}{l}8 \% \text { polymeric methylmethoxy-siloxane } \\
\text { (silicone resin) }\end{array}$ & 214 & 232 & 224 & 217 \\
\hline
\end{tabular}


laboratory, were moistened with water. Immediately afterwards the non-wetted area was measured with a caliper. Six individual values were taken on each sample, which corresponds to twelve results per prism.

\section{Water vapour diffusion resistance}

The water vapour diffusion resistance was determined in accordance with DIN EN (15803). For this purpose, two drill cores, each with a diameter of $35 \mathrm{~mm}$, were taken of a part of the cut slices. A $3 \mathrm{~mm}$ thick slice was sawn off the weathered side of each drill core and was examined by the wet-cup method. For each prism, four individual measurements were made.

\section{Water absorption by capillarity}

According to DIN EN (15801) the capillary water absorption of the samples was measured. The treated, weathered side of each natural stone sample was placed on a water-saturated underlay and the changes in weight at different time steps over a total period of $72 \mathrm{~h}$ were determined. The degree of protection $\mathrm{PD}_{\mathrm{Ci}}$ after 1 and $24 \mathrm{~h}$ measuring time was calculated from the detected values according to DIN EN (16581) using Eq. 1:

$\mathrm{PD}_{\mathrm{Ci}}(\%)=\frac{\left(Q_{\mathrm{Bi}}-Q_{\mathrm{Ai}}\right)}{Q_{\mathrm{Bi}}} \times 100$

where $Q_{\mathrm{Bi}}$ absorbed amount of water of untreated sandstone (after 2 year indoor storage) at the time $t_{i} ; Q_{\mathrm{Ai}}$ absorbed amount of water of treated sandstone at the time $t_{i}$.

\section{Water distribution measured with NMR}

With nuclear magnetic resonance (NMR) measurements, non-destructive statements can be made about the effective zone of hydrophobing agents in mineral building materials (Tullio et al. 2011; Antons 2017). For the investigations carried out in this study, a unilateral NMR device (Profile NMR-MOUSE $^{\circledR}$, PM25) was used, which allows singlesided and depth-dependent analysis (Fig. 3).

The NMR sensor consists of four permanent magnets, which generate a single-sided inhomogeneous magnetic stray field, along whose direction atomic nuclei, in this case hydrogen nuclei $\left({ }^{1} \mathrm{H}\right)$, can align themselves. A highfrequency pulse of $13.09 \mathrm{MHz}$ sent from a coil, positioned centrally between the permanent magnets, excites the hydrogen atoms in a defined measuring volume, the so-called sensitive volume (here: lateral size of $40 \mathrm{~mm} \times 40 \mathrm{~mm}$ and a thickness of $0.2 \mathrm{~mm}$ ) (Sharma et al. 2003; Casanova et al. 2011; Blümich et al. 2014; Braun and Orlowsky 2019). Via a motorised lift, mounted below the permanent magnet, the sensitive volume can be moved in predefined step sizes from the surface to the inside of the sample. After excitation, the hydrogen atoms, which are present in the sample, are detected by the coil and the received CPMG amplitude signal is transmitted to a spectrometer (Kea2), where it is converted and visualised via software in form of a diagram. The different intensities of ${ }^{1} \mathrm{H}$ detected in the sensitive volume are plotted as amplitude values with an arbitrary unit ( $y$-axis) over the sample depth in $\mu$ m ( $x$-axis).

For this study, two different NMR test setups (depth profiles and absorption tests) were chosen to evaluate the depth of the damage and the effective zone of the treated,
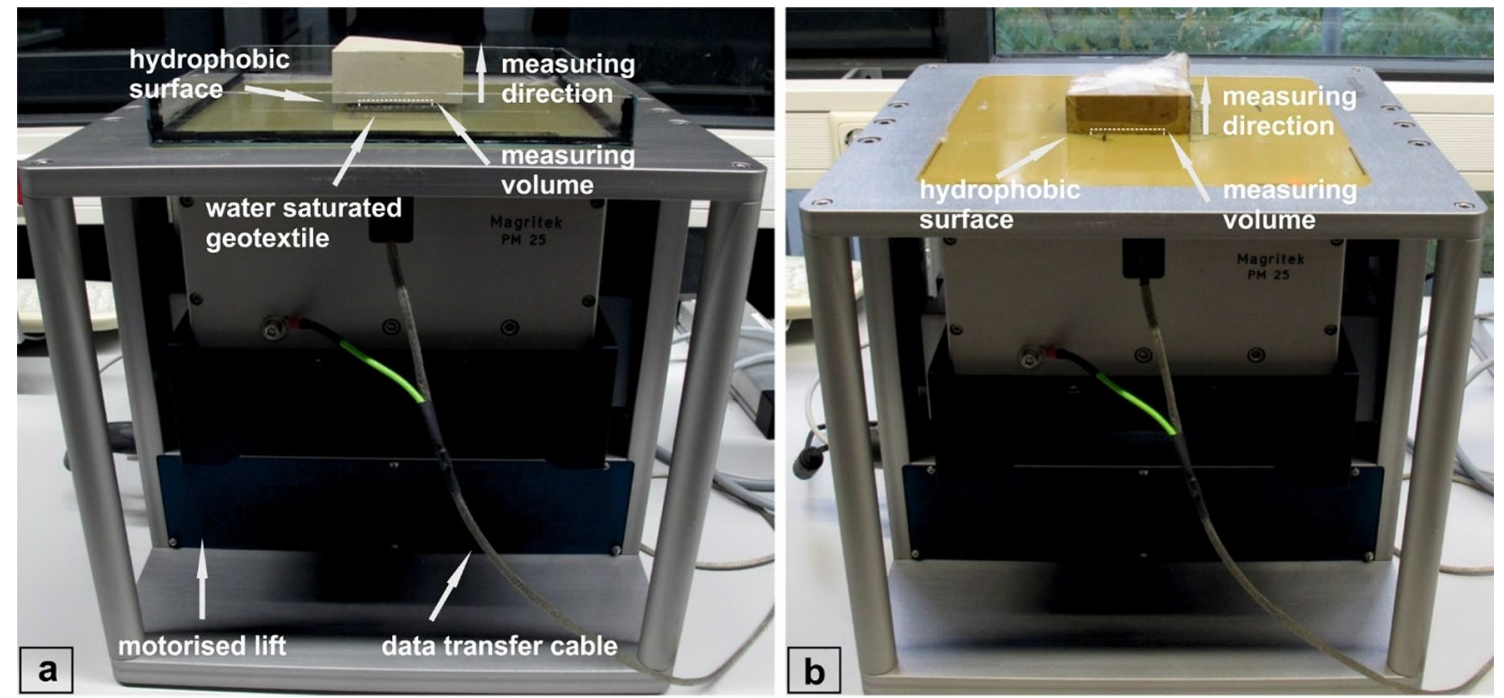

Fig. 3 Measurements of the NMR amplitude at different stone depths: a during water absorption of the dry stone - NMR absorption test and $\mathbf{b}$ on water saturated stone - NMR depth profiles 
long-term weathered natural stone surfaces. The measurements were carried out in each case using a scan number of 200 , an echo time of $80 \mu \mathrm{s}$, a repetition time of $500 \mathrm{~ms}$ and an echo number of 100 . The amplitude was determined from the mean value of the first 10 echoes of a CPMG sequence. The measured step size amounted to $200 \mu \mathrm{m}$ up to a maximum measuring depth of $5 \mathrm{~mm}$ (with a sample depth of $30 \mathrm{~mm}$ ).

For the NMR absorption tests, in laboratory conditioned dry sample material was placed with the treated side of the specimen on a water-saturated geotextile and examined over a measuring depth of $5000 \mu \mathrm{m}$ (Fig. 3a). Starting from the samples surface, the final measuring depth is reached in $200 \mu \mathrm{m}$ steps within $45 \mathrm{~min}$. This is followed by a second measurement with the same parameters. Based on these tests, the following characteristic values were determined:

- Functionality of the hydrophobic effective zone

- Damaged depth starting from the stone surface (evaluated from the second measurement between 45 and $90 \mathrm{~min}$ after capillary water absorption)

The NMR absorption tests over 90 min were repeated at a defined measuring depth within the hydrophobic layer $(600 \mu \mathrm{m})$ to additionally observe the penetration and distribution of the water inside the sample. On basis of this type of measurement, the comparison of the amplitude value (a.u.) and the associated water absorption rate $(\mathrm{kg} /$ $\mathrm{m}^{2}$ ) allows the determination of defined zones and threshold values with regard to "hydrophobic zone", "influenced zone" and "hydrophilic zone" (Braun and Orlowsky 2019). The specification of the threshold values was carried out on basis of own extensive investigations and according to the limit values specified in WTA Merkblatt 3-17-10 (2010), where treatments on natural stone surfaces should lead to a reduced water absorption lower than $0.1 \mathrm{~kg} / \mathrm{m}^{2}$.

Through NMR depth profiles, completely water-saturated samples are measured over a measuring depth of $4500 \mu \mathrm{m}$
(Fig. 3b). The samples were stored in advance in a water bath until a constant mass was reached, whereby they were immersed into water to a depth of $1 \mathrm{~cm}$, facing the treated and weathered side upwards. For the subsequent measurement, the water-saturated samples were packed in a vapourtight plastic film and placed with the hydrophobic side downwards on the NMR device. On basis of depth profiles carried out this way, it is possible to evaluate the penetration depth of the applied hydrophobing agents.

Figure 4 illustrates schematically the NMR evaluation procedure. NMR absorption tests at a defined measuring depth within the hydrophobic layer show the course of capillary water absorption behaviour over 90 min. Between 60 and 90 min of measuring time, no significant changes in the amplitudes are visible. The specific water content $\left(\mathrm{kg} / \mathrm{m}^{2}\right)$ determined after $90 \mathrm{~min}$ as well as the remaining protection degree DIN EN (16581) were compared with the amplitude values to define a specific amplitude threshold for the Baumberger Sandstone samples. The intersection of the absorption tests and depth profiles with this limit value enables the calculation of the penetration and damaged depth as well as the effective zone of the respective hydrophobing agents (described in detail in Orlowsky et al. (2020)).

Comparing the absorption tests of the samples treated with agent 5 , it becomes obvious that water also penetrates into the first $500 \mu \mathrm{m}$ of the stone surface of the treated sample stored indoors. As a result of 24 years of outdoor weathering in Eifel, this damaged depth $D_{\text {depth, NMR }}$ increases to about $1000 \mu \mathrm{m}$ (Fig. 4, left).

\section{Salt analysis and optical examinations}

The type and quantity of salts, such as sulphates, nitrates and chlorides, being present in the samples were analysed by X-Ray diffraction and potentiometric measurements using fragments taken from the surface of the natural stone to a depth of about $5 \mathrm{~mm}$.
Fig. 4 With NMR depth profiles and absorption tests statements could be made about the penetration of the hydrophobing agents and the damaged depth of the Baumberger Sandstones, the amplitude threshold (for the Baumberger Sandstone 0.1) is determined based on the correlation map in the middle
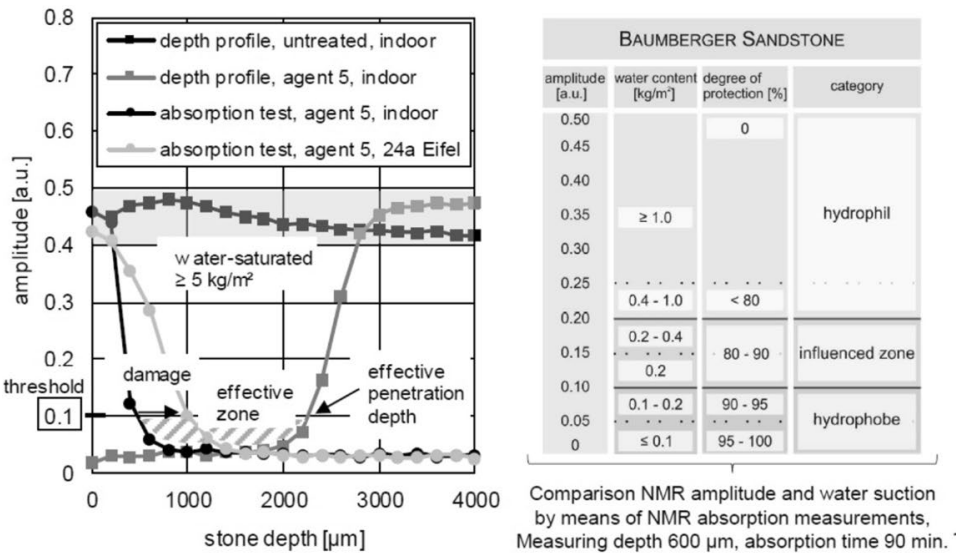

Evaluation NMR amplitudes at a defined threshold:

- penetration depth $P_{\text {depth, NMR }}$

- damaged depth $D_{\text {deptn. NMR }}$

- effective zone $E Z_{\mathrm{NMR}}$

$=P_{\text {deptn, NMR }}-D_{\text {deptr, NMR }}$

NMR absorption measurements:

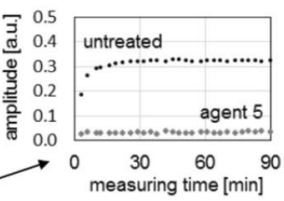


The visual appearance of the exposed prisms was documented photographically and described through damage mapping. The weathering intensity of the investigated Baumberger Sandstones was measured microscopically on selected samples prepared as thin sections and impregnated with blue-dyed resin. In addition, scanning electron microscopy (SEM) measurements conducted a further analysis with regard to near-surface weathering phenomena. The results of these investigations are explained in detail in Braun et al. (2020).

\section{Results}

\section{Comparison of the hydrophobing agents}

The performance of the eleven hydrophobing agents is compared in Table 2 using the water vapour diffusion resistance, the optical measured penetration depth and the capillary water absorption after 1 and $24 \mathrm{~h}$. The results of the untreated samples (described with agent 0 ) are also shown as reference values. For the indoor (unweathered) samples the mean values over the slices after 2 and 30 years were determined, while the mean values of the exposed specimens are composed of the single values of the three exposure sites (Dortmund, Duisburg, Eifel) with each two slices.

The hydrophobic impregnation of Baumberger Sandstone surfaces caused in general an increase in the water vapour diffusion resistance. The outdoor weathering did not lead to a significant rise in the values. Nine of the investigated eleven agents show an increase of no more than $25 \%$, only agent 2 exceeds $40 \%$. Thus the threshold value according to WTA Merkblatt 3-17 (2010), which specifies that the water vapour diffusion resistance of a sample has not be increased by more than $50 \%$ due to treatment, is complied.

The results of the optical measured penetration depths illustrate that the hydrophobing agents have only slightly penetrated the surface zone (in the range of $1 \mathrm{~mm}$ ) of the Baumberger Sandstone samples. This is also confirmed by studies on other treated Baumberger Sandstones (Funke 2020). An exception represents agent 5 with penetration depths up to $3 \mathrm{~mm}$. When determining this visible effective range differences between indoor stored and exposed specimens could not be detected either. The indicated standard deviations demonstrate the large scatter of the visible penetration depth, which occurred both between the different samples and within the six individual measurements on a sample. Accordingly, the hydrophobing agents show an uneven distribution and penetration depth in the superficial zone of Baumberger Sandstone.

Despite the low visible penetration depths, all agents cause a reduction in capillary water absorption within the first hour. However, agents 7, 8 and 9 show a significantly lower performance, which is confirmed after $24 \mathrm{~h}$ of water absorption. The best results regarding an efficient reduction in capillary water absorption after $1 \mathrm{~h}$ as well as after $24 \mathrm{~h}$ measuring time could be detected for agents 2 and 5 .

Figure 5a represents depth profiles determined with NMR on hydrophobic samples after 2 and 30 years (both were cut off from one prism according to Fig. 1) of indoor

Table 2 Comparison of the performance of the different hydrophobing agents through the water vapour diffusion resistance $\mu$, the visible penetration depth of the agents and the water absorption through capillarity after 1 and $24 \mathrm{~h}(\mathrm{SD}=$ standard deviation)

\begin{tabular}{|c|c|c|c|c|c|c|c|c|c|c|}
\hline \multirow[t]{2}{*}{ Agent } & \multicolumn{4}{|c|}{ Water vapour diffusion resistance: $\mu$} & \multicolumn{4}{|c|}{ Visible penetration depth: $P_{\text {depth, vis }}$} & \multicolumn{2}{|c|}{ Capillary water absorption: $\mathrm{WA}^{\mathrm{c}}$} \\
\hline & Indoor $^{\mathrm{a}}$ & $\mathrm{SD}_{\text {indoor }}$ & Exposed $^{b}$ & Increase & Indoor $^{\mathrm{a}}$ & $\mathrm{SD}_{\text {indoor }}$ & Exposed $^{\mathrm{b}}$ & $\overline{\mathrm{SD}_{\text {exposed }}}$ & After $1 \mathrm{~h}_{\text {indoor }}{ }^{\mathrm{a}}$ & After $24 \mathrm{~h}_{\text {indoor }}^{\mathrm{a}}$ \\
\hline & $(-)$ & $(-)$ & $(-)$ & $(\%)$ & $(\mathrm{mm})$ & $(\mathrm{mm})$ & $(\mathrm{mm})$ & $(\mathrm{mm})$ & $\left(\mathrm{kg} / \mathrm{m}^{2}\right)$ & $\left(\mathrm{kg} / \mathrm{m}^{2}\right)$ \\
\hline 0 & 21 & 3 & 21 & - & - & - & - & - & 2.14 & 5.00 \\
\hline 1 & 29 & 3 & 23 & 13 & 0.7 & 0.3 & 1.0 & 0.6 & 0.09 & 0.97 \\
\hline 2 & 32 & 6 & 30 & 43 & 0.7 & 0.1 & 1.3 & 0.7 & 0.06 & 0.34 \\
\hline 3 & 21 & 3 & 23 & 11 & 1.4 & 0.3 & 1.7 & 0.5 & 0.08 & 0.45 \\
\hline 4 & 27 & 5 & 24 & 16 & 1.2 & 1.0 & 1.5 & 0.8 & 0.08 & 0.45 \\
\hline 5 & 31 & 3 & 26 & 25 & 2.9 & 0.5 & 2.8 & 0.5 & 0.07 & 0.34 \\
\hline 6 & 28 & 7 & 27 & 31 & 1.2 & 0.5 & 1.4 & 0.8 & 0.08 & 0.52 \\
\hline 7 & 22 & 4 & 22 & 7 & 1.0 & 0.6 & 1.3 & 0.6 & 0.22 & 2.20 \\
\hline 8 & 24 & 5 & 21 & 3 & 1.4 & 0.6 & 1.0 & 0.5 & 0.73 & 5.00 \\
\hline 9 & 27 & 7 & 25 & 23 & 0.6 & 0.3 & 0.8 & 0.5 & 0.14 & 2.10 \\
\hline 10 & 22 & 3 & 23 & 12 & 1.4 & 1.3 & 1.2 & 0.9 & 0.10 & 0.61 \\
\hline 11 & 27 & 5 & 26 & 23 & 1.2 & 0.3 & 1.4 & 0.5 & 0.08 & 0.37 \\
\hline
\end{tabular}

${ }^{a}$ indoor samples $=$ mean value over all exposure times ( 2 and 30 years).

bexposed samples $=$ mean value over all exposure sites and exposure times ( 2 and 24 years).

${ }^{\mathrm{c}}$ determination of the water ingress (WA) after 1 and $24 \mathrm{~h}$ capillary absorption at the indoor samples. 
Fig. 5 Results for the treated Baumberger Sandstone samples after 2 and 30 year indoor storage: a depth profiles of the treated samples (exemplary for agent 2 and 5), b comparison of the visible penetration depth $P_{\text {depth, vis }}$ and the penetration depth $P_{\text {depth, NMR }}$ determined with NMR

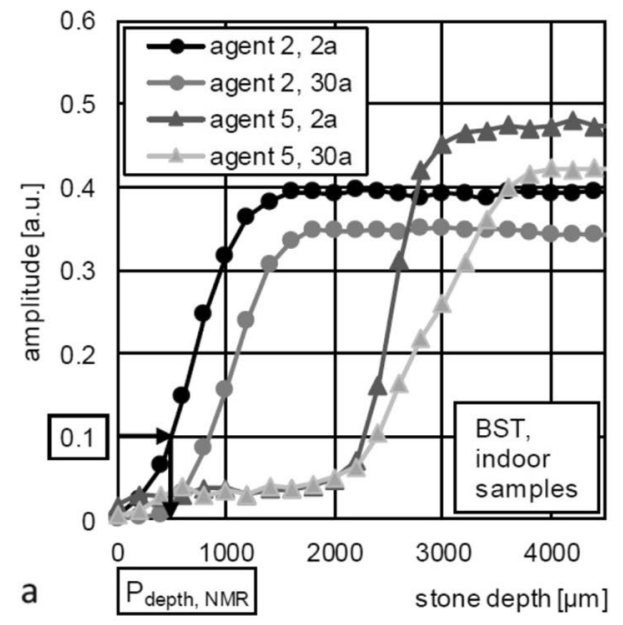

storage. The penetration depth $P_{\text {depth, NMR }}$ of each agent was determined for the previously defined threshold of 0.1 . Comparing the penetration depths $P_{\text {depth, NMR }}$ of the treated Baumberger Sandstones samples with their optical measured penetration depths $P_{\text {depth, vis, }}$, significant larger effective zones could be detected by visible measuring than by NMRtechnique. Two factors have to be taken into account in this evaluation: the penetration depths of nearly all samples are very small, which leads to inaccuracies when determining the values with a caliper. Furthermore, the samples were only moistened on the surface during the visual detection, while for NMR measurements the samples were completely saturated backside with water. Therefore, the penetration depth $P_{\text {depth, NMR }}$ indicates whether a water-repellent zone is present and effective even after prolonged exposure to moisture.

In general, the results in Fig. 5 and Table 2 illustrate the limited efficiency of the hydrophobing agents already at the indoor stored samples.

\section{Influence of outdoor weathering on water absorption}

Table 3 compares the protection degrees $\mathrm{PD}_{\mathrm{Ci}}$ of the samples at the three exposure sites (Dortmund, Duisburg and Eifel) after 2 and 24 years of weathering with the indoor stored samples, determined on the basis of capillary water absorption after 1 and $24 \mathrm{~h}$ (Eq. 1). After $1 \mathrm{~h}$ capillary suction, all indoor samples show effective hydrophobicity with values $\geq 95 \%$, after $24 \mathrm{~h}$ of water absorption the protection degrees and consequentially the hydrophobic effect already decreases. As a result of 2 years of outdoor weathering, the effective water retention was reduced at all locations, which becomes particularly evident in the $24 \mathrm{~h}$ values. After the long-term exposition of 24 years, the degrees of protection are constantly below $90 \%$. Considering the $24 \mathrm{~h}$ values, especially agents 2,3 and 11 have no long-term efficiency, while agent 5 show higher protection degrees.

More differentiated statements on water absorption can be made by determining and comparing the penetration depths $\left(P_{\text {depth, NMR }}\right)$ and damaged depths $\left(D_{\text {depth, NMR }}\right)$ based on NMR measurements, carried out at the same position on each sample (Fig. 6). Considering the penetration depths, it is noticeable that the values occasionally differ significantly between 2 and 24 years of weathering (e.g., agent 3, Dortmund), although both sample slices cut off the same prism. This distinction could be attributed to the impregnation and drying process shown in Fig. 2. Due to the upright positioning of the prisms after treating, the applied active substance had different microclimates at the side surfaces (= samples slices) during the reaction.

Already the indoor stored samples with damaged depths of around $500 \mu \mathrm{m}$ show, that water penetrates the hydrophobic area near the surface. Especially after 24 years of outdoor weathering, the depth of damage increases at the exposition sites Duisburg and Eifel. For example agent 11, exposed in Eifel, has a damaged depth even higher than the NMR measuring range, which corresponds with the determined protection degree of $0 \%$ (Table 3 ). In contrast the damaged depth of agent 5 increases due to outdoor weathering only up to a maximum of $1000 \mu \mathrm{m}$.

In some cases, the damaged depth exceeds the penetration depth (e.g., agent 2, Duisburg). Nevertheless, the damaged depth of agent 2 (Duisburg) is limited to $1100-1600 \mu \mathrm{m}$, i.e., at this depth the NMR amplitude is below 0.1 and thus an effective hydrophobicity in the sample is existing. This can be attributed to the temporary duration of water impact in the suction test: within the measuring time between 45 and $90 \mathrm{~min}$, the partially preserved hydrophobic near-surface layer causes such a reduction of the water transport that the amplitude values at the respective depth remain below the threshold value. Complementary measurements point out 
the effectiveness of the deceleration also over several hours of water exposure.

Figure 7 illustrates depth profiles of Baumberger Sandstone samples treated with agents 3 and 5 (stored indoor and exposed to Eifel) and continuously saturated with water on the backside for up to 65 days. The results show for these samples an intact water repellency of the hydrophobic layer even 24 and 30 years after application and thus no significant changes after two decades of outdoor weathering.

\section{Influence of the hydrophobing agents on weathering processes}

The macroscopic and microscopic analysis of the samples, regardless of whether an hydrophobic surface treatment
Table 3 Degree of protection $\mathrm{PD}_{\mathrm{Ci}}(\%)$ calculated from capillary water absorption after 1 and $24 \mathrm{~h}$
Fig. 6 Comparison of the penetration depth $P_{\text {depth, NMR }}$ of agents 2, 3, 5 and 11 applied on Baumberger Sandstone with their damaged depth $D_{\text {depth, NMR }}$ (measuring depth $0 \mu \mathrm{m}=$ surface of the stone)
Fig. 7 Influence of water, exposed on the backside of Baumberger Sandstone samples, on the function of the hydrophobing agents 3 and 5 after 30 years of indoor storage (a) and 24 years of outdoor weathering in the Eifel (b). The samples were water-impacted for up to 65 days, NMR depth profiles were measured after 9 , $16,23,31,38,50$ and 65 days

\begin{tabular}{|c|c|c|c|c|c|c|c|c|c|c|c|c|c|c|}
\hline \multirow[t]{3}{*}{ Agent } & \multirow{2}{*}{\multicolumn{2}{|c|}{ Indoor $^{\mathrm{a}}$}} & \multicolumn{4}{|c|}{ Dortmund } & \multicolumn{4}{|c|}{ Duisburg } & \multicolumn{4}{|c|}{ Eifel } \\
\hline & & & \multicolumn{2}{|l|}{$2 \mathrm{a}$} & \multicolumn{2}{|c|}{$24 a$} & \multicolumn{2}{|l|}{$2 \mathrm{a}$} & \multicolumn{2}{|l|}{$24 a$} & \multicolumn{2}{|l|}{$2 \mathrm{a}$} & \multicolumn{2}{|l|}{$24 a$} \\
\hline & $1 \mathrm{~h}$ & $24 \mathrm{~h}$ & $1 \mathrm{~h}$ & $24 \mathrm{~h}$ & $1 \mathrm{~h}$ & $24 \mathrm{~h}$ & $1 \mathrm{~h}$ & $24 \mathrm{~h}$ & $1 \mathrm{~h}$ & $24 \mathrm{~h}$ & $1 \mathrm{~h}$ & $24 \mathrm{~h}$ & $1 \mathrm{~h}$ & $24 \mathrm{~h}$ \\
\hline 2 & 97 & 92 & 92 & 76 & 81 & 50 & 90 & 73 & $76^{\mathrm{b}}$ & $42^{\mathrm{b}}$ & 86 & 63 & 81 & 52 \\
\hline 3 & 96 & 90 & 87 & 64 & 78 & 58 & 92 & 89 & 77 & 60 & 86 & 80 & 78 & 57 \\
\hline 5 & 96 & 93 & 92 & 87 & 81 & 67 & & & 85 & 84 & 93 & 90 & 80 & 77 \\
\hline 11 & 96 & 92 & 87 & 64 & 73 & 20 & 85 & 54 & 63 & 7 & 92 & 80 & 58 & 0 \\
\hline
\end{tabular}

${ }^{a}$ indoor samples $=$ mean value over all exposure times ( 2 and 30 years).

${ }^{b} 17$ years instead of 24 year outdoor weathering.
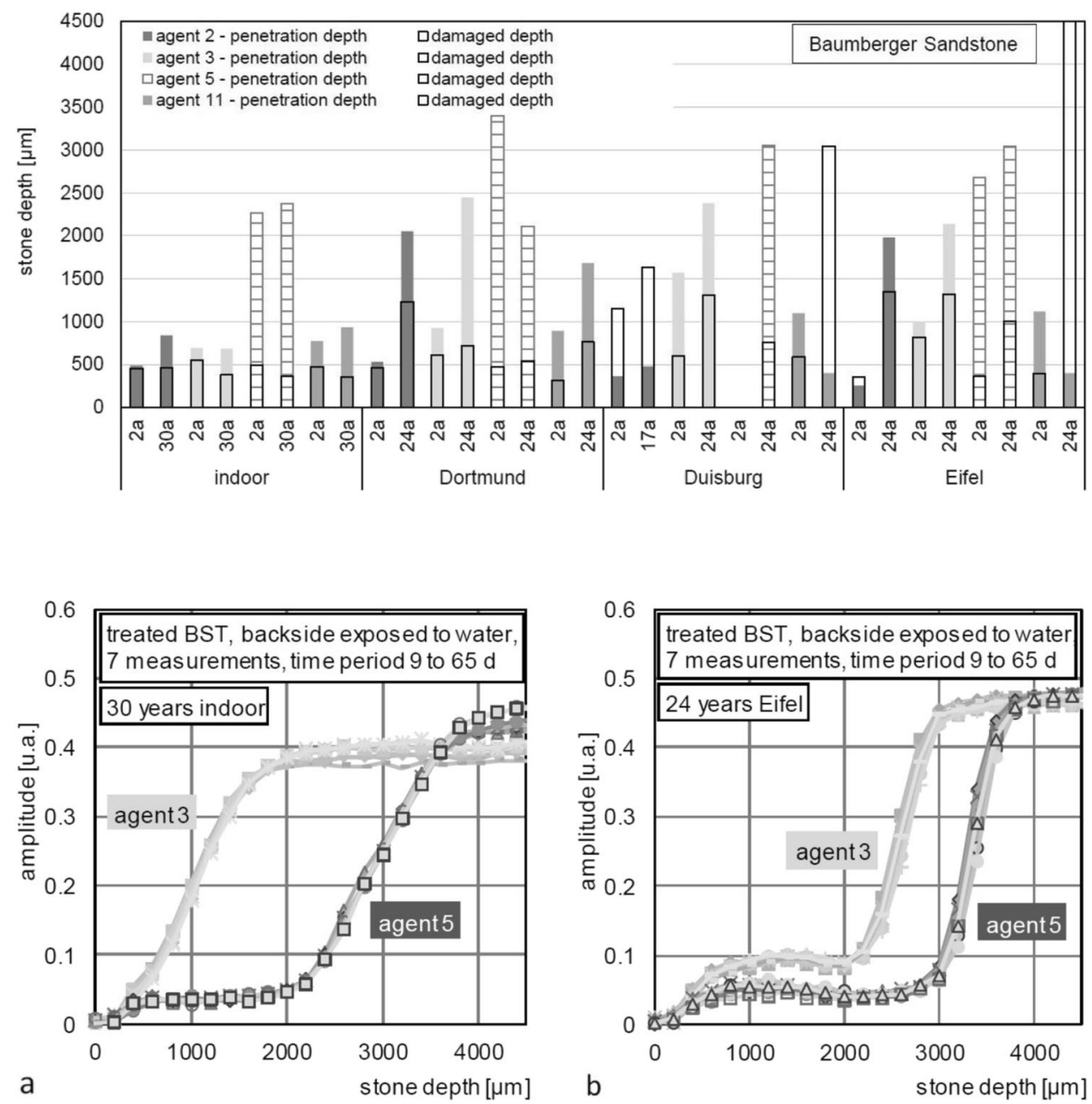
has been carried out and which hydrophobing agent was chosen, revealed the occurrence of weathering phenomena such as spalling, surface roughening, sanding, gypsum efflorescence, formation of crusts and scales, soiling and biogenic growth after 24 years of outdoor weathering (Fig. 8 and Braun et al. 2020). The used hydrophobing agents did not cause a clearly detectable deceleration of the weathering processes on the Baumberger Sandstone, although the resulting capillary water absorption values partially showed water-repellent effects. This can be attributed to the fact that already before outdoor weathering (even at the indoor samples) water was able to penetrate the surface-near area (in the first $500 \mu \mathrm{m}$, Fig. 6) and could cause weathering processes.
This insufficient functionality of the hydrophobing agents, which presumably already existed directly after application, leads to an ingress of water through the pores in the uppermost part of the stones.

\section{Conclusion}

On 102 Baumberger Sandstone prisms (=204 slices), with different applied treatments and weathered for various long periods of time, comprehensive laboratory investigations were carried out at the Chair of Building Materials (TU Dortmund University). Damages occurring via long-term
Fig. 8 Weathering damages on Baumberger Sandstone (top left to bottom right): salt efflorescence, darkening of the surface with an intact hydrophobic layer underneath, biogenic growth, sanding, spalling, scaling, formation of black crusts. The formation of superficial scales at depths of 1.0 to $1.5 \mathrm{~mm}$ occurred at the untreated as well as the treated samples (samples: agent 6, 17 year Duisburg / agent 5, 24 year Duisburg / agent 4, 24 year Dortmund / agent 8, 24 year Dortmund / agent 11, 24 year Duisburg / agent 3, 24 year Duisburg / agent 2, 24 year Dortmund)
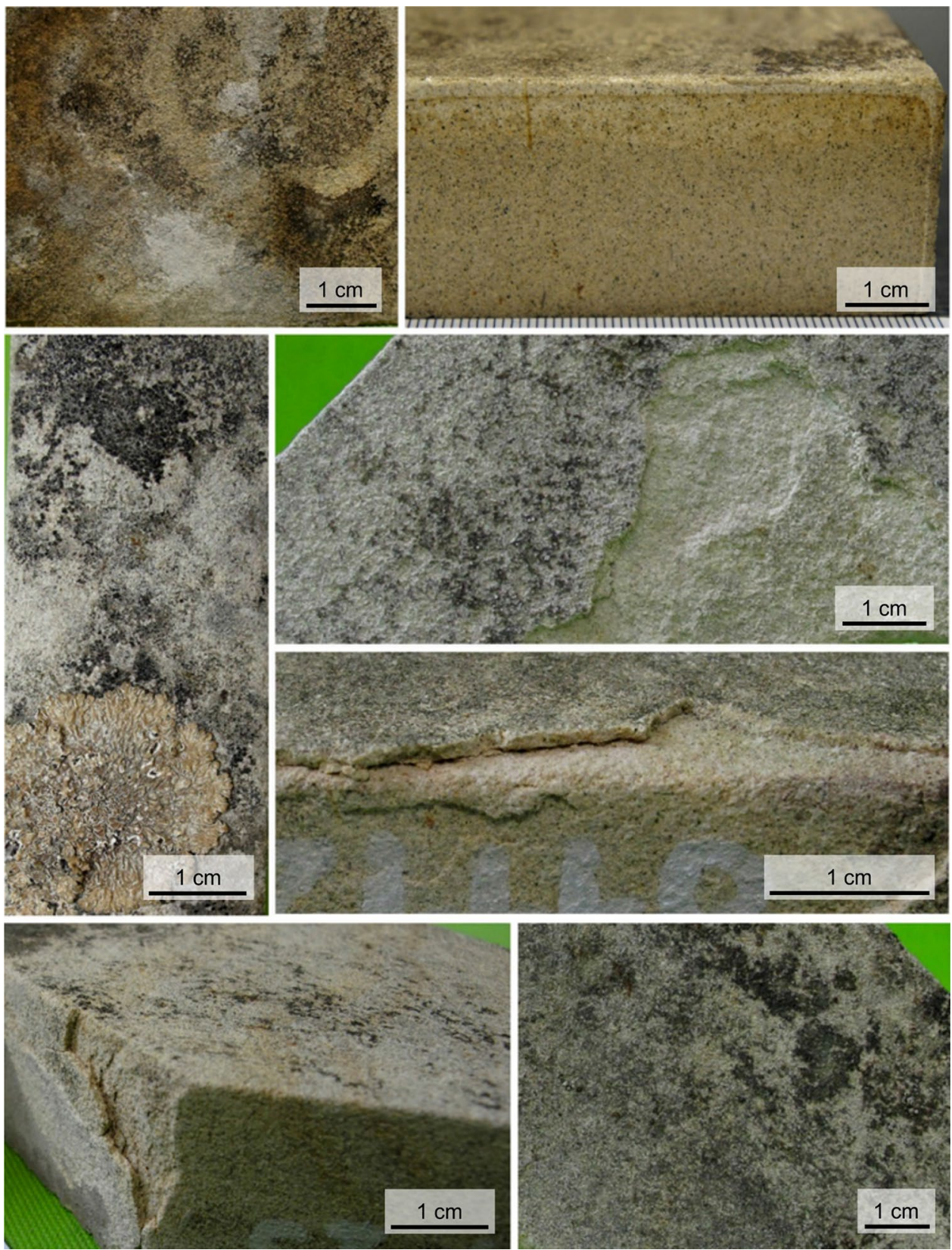
exposure were mapped and documented and the total colour and colour changes were determined. Water vapour measurements were carried out and the water absorption was investigated by pipe method (DIN EN 16302) and capillarity (DIN EN 15801). Furthermore, penetration depths were measured optically and through NMR, and the near-surface damage depth was defined by NMR measurements during capillary water absorption. Mercury pressure porosimetry, salt analysis and microscopic examinations completed the experimental program.

Based on this, the following conclusion can be made regarding the performance of hydrophobic surface treatments on Baumberger Sandstones:

- The penetration depths of the hydrophobing agents are very low, with a maximum of $3 \mathrm{~mm}$, and in some cases an even, continuous water-repellent layer does not exist. Thus a prolonged impregnation process may be a possibility of improvement.

- Despite these low penetration depths, a water-repellency of the samples is existing, whereby it decreases directly on the natural stone surface over a long-term water impact of $24 \mathrm{~h}$.

- Despite the hydrophobic surface treatment, water can penetrate the surface (first $500 \mu \mathrm{m}$ ) of the Baumberger Sandstone, which causes weathering processes of the natural stones. After 24 years of outdoor weathering at the exposure sites Dortmund, Duisburg and Eifel, all prisms show clear signs of weathering. The eleven examined hydrophobing agents do not significantly reduce these water-induced processes. In addition to the optical and microscopic analysis results, this is also shown in the increase of the damaged depth $D_{\text {depth, NMR }}$.

- Even after 24 years of outdoor weathering, the waterrepellent function of the hydrophobing agents remains within their effective zone.

- Due to the small and uneven distributed effective zone of the hydrophobing agents and the resulting not significant decrease of the natural stone weathering, a hydrophobic surface treatment of Baumberger Sandstones appears on basis of this study as not suitable.

Nevertheless, the available examination material and the well-established new measuring and evaluation methods offer the investigation of further important questions, such as:

- What influence has the duration of the penetrating water and the water pressure on the water-repellency of the samples?

- Are there differences in the weathering processes of the Baumberger Sandstone depending on the inclination of the stone surface? In the previous studies the verti- cally oriented side surfaces have been analysed, further examinations will focus on the inclined roof surfaces and the comparison of their results with these of the side surfaces (see Fig. 1).

- Which careful cleaning methods are suitable to remove the surface deposits on the long-term weathered natural stone surfaces?

Acknowledgements We would like to thank Prof. Dr. Stefan Brüggerhoff, for providing the stone samples for our investigations. This work was performed as part of a project funded by the Deutsche Forschungsgemeinschaft (DFG, German Research Foundation)— project number 342881843

Author contributions Conceptualisation, FB and JO; methodology, JO and $\mathrm{FB}$; validation $\mathrm{JO}, \mathrm{FB}$ and $\mathrm{MG}$; investigation, $\mathrm{FB}$; writing-original draft preparation, JO; writing-review and editing, $\mathrm{MG}$ and $\mathrm{FB}$; visualisation, JO, FB and MG; supervision, JO; project administration, $\mathrm{JO}$; funding acquisition, JO. All the authors have read and agreed to the published version of the manuscript.

Funding Open Access funding enabled and organized by Projekt DEAL.

\section{Declarations}

Funding This work was performed as part of a project funded by the Deutsche Forschungsgemeinschaft (DFG, German Research Foundation)—project number 342881843.

Conflict of interest The authors declare no conflict of interest. The funders had no role in the design of the study; in the collection, analysis, or interpretation of data; in the writing of the manuscript; or in the decision to publish the results.

Open Access This article is licensed under a Creative Commons Attribution 4.0 International License, which permits use, sharing, adaptation, distribution and reproduction in any medium or format, as long as you give appropriate credit to the original author(s) and the source, provide a link to the Creative Commons licence, and indicate if changes were made. The images or other third party material in this article are included in the article's Creative Commons licence, unless indicated otherwise in a credit line to the material. If material is not included in the article's Creative Commons licence and your intended use is not permitted by statutory regulation or exceeds the permitted use, you will need to obtain permission directly from the copyright holder. To view a copy of this licence, visit http://creativecommons.org/licenses/by/4.0/.

\section{References}

Antons U (2017) Untersuchungen zur Dauerhaftigkeit hydrophober Schichten im Beton mittels NMR. RWTH Aachen University, Dissertation

Blümich B, Haber-Pohlmeier S, Zia W (2014) Compact NMR. Walter de Gruyter, Berlin

Braun F (2021) Zur Ermittlung des Langzeitverhaltens hydrophobierter Natursteinoberflächen unter dem Einfluss der natürlichen 
Verwitterung. TU Dortmund University, Dissertation. https://doi. org/10.17877/DE290R-22199

Braun F, Orlowsky J (2019) Non-destructive detection of the efficiency of long-term weathered hydrophobic natural stones using singlesided NMR. J Cult Herit 41:51-60. https://doi.org/10.1016/j.culher.2019.07.005

Braun F, Orlowsky J, Brüggerhoff S (2020) Analyzing near-surface regions of hydrophobic and long-term weathered natural stones at microscopic scale. Heritage 3(2):457-473. https://doi.org/10. 3390/heritage3020027

Brüggerhoff S, Wagener-Lohse C (1989) Gesteinsverwitterung in Freilandversuchsfeldern - Erfahrungen mit ihrer Errichtung und Nutzung. Bautenschutz + Bausanierung 12(5):76-80

Casanova F, Perlo J, Blümich B (2011) Single-sided NMR. SpringerVerlag, Berlin, Heidelberg

Di Tullio V, Proietti N, Capitani D, Nicolini I, Mecchi AM (2011) NMR depth profiles as a non-invasive analytical tool to probe the penetration depth of hydrophobic treatments an inhomogeneities in treated porous stones. Anal Bioanal Chem 400(9):31513164. https://doi.org/10.1007/s00216-011-4968-5

DIN EN 15801:2010-04 Conservation of cultural property - test methods - determination of water absorption by capillarity; German version EN 15801:2009. Beuth Verlag GmbH, Berlin

DIN EN 15803:2010-04 Conservation of cultural property - test methods - determination of water vapour permeability $(\delta p)$; German version EN 15803:2009. Beuth Verlag GmbH, Berlin

DIN EN 16302:2013-04 Conservation of cultural heritage - test methods - measurement of water absorption by pipe method; German version EN 16302:2013. Beuth Verlag, Berlin
DIN EN 16581:2015-03 Conservation of cultural heritage - surface protection for porous inorganic materials - laboratory test methods for the evaluation of the performance of water repellent products; German version EN 16581:2014. Beuth Verlag, Berlin

Funke F (2020) Oberflächenbehandlung von Baumberger Kalksandstein. Denkmalpflege in Westfalen-Lippe - Farbfassungen und Architekturoberflächen 26(2):41-45

Hafner W (1988) Baumberger Kalk-Sandstein. Steinmetz + Bildhauer: Handwerk, Technik, Industrie 7:21-24

Mirwald PW (1986) Umweltbedingte Gesteinszerstörung untersucht mittels Freilandverwitterungsexperimenten. Bautenschutz + Bausanierung, 24-27

Orlowsky J, Braun F, Groh M (2020) The influence of 30 years outdoor weathering on the durability of hydrophobic agents applied on Obernkirchener Sandstones. Buildings 10(18):1-18. https://doi. org/10.3390/buildings 10010018

Sharma S, Casanova F, Wache W, Segre A, Blümich B (2003) Analysis of historical porous building materials by the NMR-MOUSE ${ }^{\circledR}$. Magne Res Imag 21(3-4):249-255. https://doi.org/10.1016/ S0730-725X(03)00132-2

WTA Merkblatt 3-17 (2010) Hydrophobierende Imprägnierung von mineralischen Baustoffen. WTA Merkblatt 3-17-10/D:2010-06. Fraunhofer IRB Verlag, Stuttgart

Publisher's Note Springer Nature remains neutral with regard to jurisdictional claims in published maps and institutional affiliations. 